\title{
O CUIDADO DE ENFERMAGEMAO PACIENTE CRÍTICO NA PERCEPÇÃO DA FAMÍLIA
}

\author{
Rúbia Manetti Mezzarobaํㅡㅁ Vívian Maria de Freitas², Kátia Renata Antunes Kochla ${ }^{3}$
}

\begin{abstract}
RESUMO: Estudo exploratório-descritivo, realizado em um Centro de Terapia Semi-intensiva em um Hospital Público de grande porte de Curitiba. Objetivos: compreender o significado do cuidado de Enfermagem para o familiar do paciente crítico e identificar se a equipe de Enfermagem atende às expectativas da família. Os sujeitos do estudo foram familiares de pacientes internados no período de fevereiro de 2008. A coleta de dados foi realizada por meio de entrevistas. Os dados foram organizados em categorias. Para os sujeitos o cuidado de enfermagem está atrelado às ações tecnicistas e à atenção que a equipe dedica ao paciente. A família considera que, se a equipe cuidar com atitudes de carinho e de ternura, os resultados serão positivos para a recuperação do paciente. Uma parte significante dos entrevistados sinalizou que suas expectativas foram atendidas e outra considerou que o contato com a equipe não foi satisfatório. Este estudo mostrou a necessidade de uma reflexão, pela equipe de enfermagem, sobre a importância da percepção da família quanto ao cuidado. PALAVRAS-CHAVE: Relações profissional-família; Cuidados intensivos; Cuidados de enfermagem; Equipe de enfermagem.
\end{abstract}

\section{THE NURSING CARE TO THE CRITICAL PATIENT IN FAMILY’S PERCEPTION}

\begin{abstract}
Descriptive-exploratory study, performed in a Semi-intensive Therapy Center (CTSI) in a large Public University Hospital in Curitiba. The objectives were to understand the meaning of nursing care to the critical patient's relatives and to identify if the nursing team meets family's expectations. The study's subjects were relatives of patients who were hospitalized in February 2008. Data survey was performed through interviews and organized in categories. For the subjects, nursing care is related to technical actions and to the attention the team dedicates to patient. Families consider that if the team takes care with love and tenderness, the results will be positive to patient recovery. A significant part of interviewed people indicated that their expectations were met and another part considered nursing team contacts were unsatisfactory. This study showed the necessity of a nursing team reflection on the importance of family's perception regarding care.

KEYWORDS: Professional-family relations; Intensive care; Nursing care; Nursing team.
\end{abstract}

\section{EL CUIDADO DE LAENFERMERÍAAL PACIENTE CRÍTICO SEGÚN LAPERCEPCIÓN DE LAFAMILIA}

RESUMEN: Estudio exploratorio descriptivo, realizado en un Centro de Terapia Semintensiva (CTSI) en un Hospital Público de gran porte de Curitiba. Objetivo: comprender el significado del cuidado de Enfermería para el familiar del paciente crítico e identificar si el equipo de Enfermería atiende a las expectativas de la familia. Los sujetos del estudio fueron familiares de pacientes internados en el periodo de febrero de 2008. La colecta de datos fue realizada mediante entrevistas. Los datos fueron organizados en categorías. Para los sujetos el cuidado de enfermería está relacionado con las acciones tecnicistas y con la atención que el equipo dedica al paciente. La familia considera que, si el equipo cuida con actitudes de cariño y de ternura, los resultados serán positivos para la recuperación del paciente. Una parte significante de los entrevistados señalizó que sus expectativas fueron atendidas y otra consideró que el contacto con el equipo no había sido satisfactorio. Este estudio mostró la necesidad de una reflexión, por el equipo de enfermería, sobre la importancia de la percepción de la familia en cuanto al cuidado.

PALABRAS CLAVE: Relaciones profesional-familia; Cuidados intensivos; Cuidados de enfermería; Equipo de enfermería.

${ }^{1}$ Graduanda do Curso de Graduação de Enfermagem da Universidade Tuiuti do Paraná-UTP.

${ }^{2}$ Graduanda do Curso de Graduação de Enfermagem da UTP.

${ }^{3}$ Mestre em Enfermagem. Docente do Curso de Enfermagem da Faculdade de Ciências Biológicas e da Saúde da UTP.

Autor correspondente:

Kátia Renata Antunes Kochla

Rua Sydnei A. Rangel Santos, 238 - 82010-330 - Curitiba-PR

Recebido: 25/04/09

Email:kanurse@hotmail.com

Aprovado: 16/09/09 


\section{INTRODUÇÃO}

As Unidades de Terapia Intensiva são destinadas à prestação de assistência especializada a pacientes em estado crítico e, para os quais, se faz necessário o controle rigoroso dos parâmetros vitais, cuidados intensivos, conhecimento técnico, destreza manual e assistência de enfermagem contínua.

O paciente crítico perde o contato direto com seus familiares, é destituído temporariamente da sociedade, de suas atividades e rotinas, tendo que se relacionar com desconhecidos e ficar exposto a situações constrangedoras, além de deparar-se com outros pacientes, por vezes em condições piores que a sua. Ele pode enfrentar ainda, fatores que geram medo e angústia e o deixam mais fragilizado e debilitado no seu estado emocional. Nesse sentido, o paciente precisa ser respeitado e atendido em suas necessidades e direitos, com individualidade, privacidade, presença da família e de profissionais que o acolham e o façam sentir-se o mais confortável possível.

Acredita-se que o cuidado precisa ser sistematizado e holístico, para promover a qualidade da assistência. O processo de cuidar não pode ser pautado apenas na identificação dos sinais e sintomas clínicos da doença, mas nas modificações que ocorrem na estrutura dos seres humanos as quais o abalam em sua totalidade ${ }^{(2)}$.

Neste contexto, faz-se necessário ressaltar que

Ser é cuidar, e as várias maneiras de estar-no-mundo compreendem diferentes maneiras de cuidar. Para se tornar um ser de cuidado, um cuidador, o ser precisa, primeiro, ter experienciado o cuidado, ou seja, ter sido cuidado. A capacidade de cuidar está, portanto, relacionado ao quanto e como o ser foi cuidado. Através do cuidado, percebe a existência de outros além do que se é; o outro dá o sentido do $\mathrm{Eu}^{(3: 19)}$.

O cuidado de Enfermagem deve constituir-se na interação, no contato com o paciente e no resgate do cuidado humano em que a família deve ser incluída no processo de cuidar. Assim o cuidado deve atender às necessidades dos pacientes e familiares, ajudandoos a compreender, a aceitar e a enfrentar a doença, o tratamento e as consequências que essa nova situação impõe à vida familiar ${ }^{(3)}$.

Para a família, o processo de hospitalização pode gerar sofrimento e estresse e, nesse contexto, o enfermeiro e sua equipe devem estar capacitados a reconhecer a relação com o familiar, estabelecendo atitudes de sensibilidade e empatia. A família tem o direito de ser inclusa nos cuidados de saúde, já que para o bem-estar do paciente, a presença dela é significativa.

$\mathrm{O}$ estudo ${ }^{(5)}$ enfoca que as necessidades dos familiares de pacientes críticos têm sido investigadas sob diversos aspectos, e os resultados dos estudos contribuem para a conscientização de que o atendimento das necessidades das famílias é responsabilidade que não pode ser ignorada por nenhum hospital.

A tendência atual das políticas sociais e das políticas de saúde é enfocar a família e não o indivíduo isoladamente como unidade de atendimento. Porém, a formação dos profissionais de saúde, na maioria das vezes, é voltada para o agir a partir de uma visão individualizada e objetivada do corpo e da doença, com base no modelo biomédico. Contrariando esse paradigma, os profissionais devem estar aptos às novas demandas da assistência, interagindo e formando um vínculo maior com a família( ${ }^{(5)}$.

O cuidado de enfermagem com a família deve ir além de permitir a visita do familiar, deve incluir o estabelecimento de uma relação de confiança e de ajuda, na qual a equipe de enfermagem tem a função de identificar as reais necessidades dos familiares, facilitando o tratamento do paciente.

A família deve ser entendida, neste contexto, como uma unidade social conectada ao paciente através de laços afetivos e também,

como um aliado importante da equipe, podendo atuar como um recurso por meio do qual o paciente pode reafirmar e, muitas vezes, recuperar sua importância no tratamento, de forma a investir nas suas possibilidades de recuperação(6:28).

O familiar vivencia ao lado do doente as etapas do cuidar de enfermagem e muitas vezes se sente ansioso, cheio de dúvidas em relação aos cuidados prestados por esta equipe durante o processo de hospitalização. Reconhecendo o papel que a família possui no tratamento e no cuidado prestado ao paciente de uma maneira geral e do paciente crítico em particular, o presente estudo tem como questão norteadora: Qual o significado do cuidado de enfermagem na percepção da família do paciente crítico? Como objetivos: Compreender o significado do cuidado de Enfermagem para o familiar do paciente crítico; Identificar se a equipe de Enfermagem atende às expectativas da família.

\section{METODOLOGIA}

Trata-se de um estudo exploratório-descritivo 
de abordagem qualitativa que intenciona compreender o significado do cuidado e identificar as expectativas da família quanto à equipe de Enfermagem, através de um processo de reflexão dos discursos dos sujeitos da pesquisa.

O estudo foi desenvolvido na sala de espera do Centro de Terapia Semi-intensiva-CTSI de um Hospital Público Universitário de grande porte localizado na cidade de Curitiba.

Participaram do estudo sete familiares de pacientes que estavam internados no mês de Fevereiro de 2008. Os critérios para inclusão foram: ser maior de 18 anos, ter familiar internado no local de estudo, independente do grau de parentesco, concordar voluntariamente em participar da pesquisa mediante assinatura do Termo de Consentimento Livre e Esclarecido conforme a Resolução n. 196/96 do Conselho Nacional de Saúde. A pesquisa foi aprovada pelo Comitê de Ética e Pesquisa do hospital citado com o Registro CEP: 1575.240/2007-11.

Por se tratar de uma abordagem qualitativa, o número de sujeitos não foi limitado, o que permite ao pesquisador encerrar a coleta de dados a partir da saturação das falas.

A coleta de dados foi realizada por meio de entrevista semiestruturada composta por questões de caracterização dos sujeitos e questões abertas que indagavam sobre o entendimento do cuidado de Enfermagem com o paciente, como a família percebe e sente o cuidado com o paciente, quais as ações da equipe de Enfermagem que são consideradas importantes para a recuperação e como é o contato do familiar com a equipe de Enfermagem. Os sujeitos do estudo foram convidados e contactados a participar do estudo previamente e as entrevistas agendadas com antecedência. Os dados foram registrados através de entrevistas audiogravadas conforme a autorização dos entrevistados, posteriormente transcritas e submetidas ao processo de análise.

Os dados coletados foram analisados qualitativamente através da análise temática proposta por Minayo $^{(9)}$. A fase de análise de informações tem por objetivo

Estabelecer uma compreensão dos dados coletados, confirmar ou não os pressupostos da pesquisa e ou responder as questões formuladas e ampliar o conhecimento sobre o assunto pesquisado, articulando com o contexto cultural da qual faz parte ${ }^{(9: 69)}$.

Nesta fase, foram seguidos os passos preconizados por Minayo ${ }^{(9)}$ que são: Ordenação dos dados - consistiu na transcrição das entrevistas gravadas, leitura e releitura do material, organização dos relatos com início de classificação; Classificação dos dados - definiu-se no processo de leitura do material obtido para estabelecer questões importantes e elaborar as categorias do estudo. Foi necessário mergulhar nas falas dos familiares e apreender as significações expressadas nos seus discursos. Todo o material foi aproveitado para constar na análise, pois cada segmento de fala está relacionado ao objetivo do trabalho e responde à questão da pesquisa. Essa fase exigiu a leitura e releitura para interpretar as reais significações e delinear as categorias que constituirão o corpus do trabalho; e Análise Final - consistiu em relacionar os discursos aos referenciais teóricos da pesquisa, procurando elucidar a questão norteadora da investigação. É nessa etapa que foram articuladas as idéias entre pesquisadores e literatura, permeadas pelas falas dos sujeitos da pesquisa.

\section{COMPREENDENDO OS DISCURSOS}

A idade dos entrevistados variou entre 18 e 71 anos, sendo seis do sexo feminino e um do sexo masculino. Quatro sujeitos eram filhos dos pacientes internados, duas eram esposas e uma irmã. O grau de escolaridade predominante foi o ensino médio incompleto. Os entrevistados foram identificados por nomes de flores para preservar a sua identidade.

$\mathrm{Na}$ análise dos dados das entrevistas originaram-se as seguintes categorias: $\mathrm{O}$ cuidado de enfermagem no entender do familiar; Ações de enfermagem que contribuem para a recuperação do paciente; $\mathrm{O}$ contato da equipe de enfermagem com a família: um momento importante.

\section{$O$ cuidado de enfermagem no entender do familiar}

Para o familiar, o cuidado de enfermagem está atrelado às ações tecnicistas e à atenção que a equipe dedica ao paciente. É comum, nos discursos dos sujeitos, a citação das técnicas de enfermagem como: administrar a medicação, realizar a higiene, fazer curativos, verificar sinais vitais, aplicar medidas de conforto e alimentação. Igualmente, os familiares observam que o cuidado também se reflete na forma do profissional se dirigir ao paciente, a maneira de falar, olhar, dar atenção, se preocupar: 
Eles coletam material para exame, cuidam dos curativos, a pressão, a febre, alimentação. [...] Às vezes ali não é tanto a doença, [...] uma palavra de conforto às vezes vale mais que um remédio (Margarida).

Olhar, dar medicação na hora certa, carinho e atenção com o paciente porque com isso ele vai se recuperar mais rápido (Cravo).

[...] é tarem perto prestando atenção em qualquer coisa que ela precise, [...] de repente a gente chega no quarto tem alguma enfermeira conversando com ela prá estimular um pouco também [...] tô sentindo que ela tá sendo bem cuidada toda vez que nós vimos aqui ela tá bem limpinha, higienizada, o quarto tá sempre em ordem (Lírio).

[...] tão sempre limpando ele, tão ajudando ele a se virá na cama, dando remédio, dando alimentação dele, prá ele se sentir bem, é isso que tô vendo de importante (Orquídea). cuidado,

Complementando a visão dos sujeitos sobre o

observa-se que o cuidar não comporta somente a excelência na execução das intervenções de enfermagem. Mas, também a condição de que a cuidadora deverá em suas ações expressar a sua sensibilidade fazendo com que o ser cuidado perceba seu interesse e respeito, transmitindo-lhe segurança ${ }^{(1: 1)}$.

Porém, algumas das ações desenvolvidas pela equipe de enfermagem apresentam enfoque tecnicista, esquecendo que o cuidar como característica humana deve se basear na afetividade, na empatia, na solidariedade, no sentido de cuidar do outro como gostaria de ser cuidado.

Um dos sujeitos relata uma situação desagradável durante o cuidado ao paciente.

[...] eu já presenciei eles cuidando do meu marido, algumas enfermeiras são bem tranquilas, outras não, $[. .$.$] se eu vou mexer com um paciente, uma$ pessoa que tá doente, vou tratar com delicadeza, $e$ ontem eu presenciei eles cuidando desse senhor que tava bem mal, não muito delicada, então fui prá casa até meio chateada com aquilo. [...] ele que um dia tava meio chateado, porque as enfermeiras tava meio estressada assim, mas foi um dia ou dois, só (Violeta).

Diante dessa fala, verifica-se que o sujeito se colocou na posição do profissional de enfermagem, pois mencionou que o cuidado devia ser realizado de forma "delicada", o que pontua a sua ideia de como o cuidador deve ser. Porém, a equipe está inserida em uma rotina diária e não percebe que o familiar tem uma visão diferenciada de um serviço de saúde, que os pequenos gestos como um cumprimento, um sorriso, um aperto de mão, uma demonstração de afeto são valiosos diante da situação em que se encontra o paciente.

Neste sentido:

Quanto mais o clima for de conforto e confiança, mais a experiência pode ser positiva porque os gestos de atenção e cuidado ficarão presentes sempre na lembrança dos familiares ${ }^{(10: 428)}$.

\section{Ações de enfermagem que contribuem para a recuperação do paciente}

Atualmente tem-se discutido que o cuidado vai além das ações técnicas, e que estas devem estar associadas a manifestações de carinho, de ternura, de estímulo e de dedicação da equipe. Assim, observa-se que as falas dos sujeitos refletem essa tendência, o que contribui para a recuperação do paciente:

O amor, o carinho que dão ao paciente, a dedicação, é muito importante [...]. Pela segunda vez que ele tá aqui. Oh! Excelente, nenhum problema. Até eu faço tudo o possível prá encaixar ele nesse hospital, tudo possível, é a segunda vez que ele vem (Rosa).

Na opinião do familiar, se a equipe cuidar com carinho do paciente os resultados serão positivos para a sua recuperação:

Acho que ainda é o carinho, eu acho, porque se o paciente tá sentindo o carinho das pessoas por ele, ajuda bastante. Com certeza o paciente se recupera mais rápido, fica mais feliz também (Violeta).

Acredito que seja a maneira deles tratar os pacientes com carinho, dedicação e atenção, isso vai estimular a vontade de viver dos pacientes (Cravo).

O carinho, citado pelos sujeitos, está relacionado ao conforto emocional do paciente que tem como foco o cuidar com dedicação, respeito, atenção, considerando 
suas crenças, valores, desejos e expectativas de melhora do seu estado de saúde.

Quando se inclui cuidado e amor na profissão, descobrese que a enfermagem é mais do que apenas um trabalho, e sim uma ocupação de dar e receber, de crescer e aprender por toda a vida ${ }^{(11: 611)}$.

Os entrevistados também destacaram que o diálogo e o estímulo são necessários no cuidado com o paciente:

Eu acho que é o incentivo que eles dão para ele melhorar, ele tá bem de espírito (Hortênsia).

A conversa que a enfermeira tem de estimular, que nem minha mãe tá num processo delicado então tem horas que ela dorme e as enfermeiras chegam conversam, falam, acho que isso é o estímulo (Lírio).

O diálogo possibilita a aproximação com a subjetividade, promove o estímulo ao paciente para superar o período de permanência em uma unidade de cuidados intensivos, bem como é essencial para a construção do envolvimento que a equipe deve desenvolver com o paciente e a sua família.

Nesta linha,

o ambiente da UTI tornar-se-á menos impessoal para o doente e seus familiares quando o diálogo estiver aberto para ambos, quando houver uma interação entre os doentes e seus familiares, entre eles, o ser cuidador de enfermagem e entre os cuidadores de enfermagem da $\mathrm{UTI}^{(12: 253)}$.

Dessa forma, o diálogo com uma terminologia clara, compreensível, reservando tempo para ouvir as preocupações do paciente, medos e angústias, contribui positivamente para sua recuperação e gera maior confiança na equipe na visão do familiar.

\section{O contato da equipe de enfermagem com a família: um momento importante}

A obtenção de informações pela família nem sempre é tarefa fácil. Horários rígidos de visitas, limitação de familiares visitantes, equipe de saúde apressada e atarefada, entre outros, contribuem para o aumento da dificuldade e da ansiedade em saber informações a respeito do familiar hospitalizado. Nesse sentido, a presença da equipe de enfermagem durante o horário de visita se faz necessária para explicar os cuidados realizados, planejamento de ações a serem desenvolvidas e esclarecer as dúvidas que assolam os familiares.

Um estudo realizado em instituições públicas e privadas avaliou as necessidades dos familiares de pacientes críticos, dentre elas destacam-se: sentir que o pessoal do hospital se interessa pelo paciente, receber explicações que possam ser compreendidas, saber quais profissionais estão cuidando do paciente, ter orientações gerais sobre a UTI na primeira visita, sentir-se aceito pela equipe, ter horário de visita modificado em situações especiais, ter alguém que se preocupa com a saúde do paciente e ajudar a cuidar dele ${ }^{(4)}$.

Nas falas que seguem, infere-se que a equipe estabeleceu bom contato com os familiares e eles estão satisfeitos com as informações recebidas:

Eles atendem super bem, explicam direitinho tudo sobre a doença, sobre os procedimentos que tão fazendo e é o que a gente espera mesmo da equipe de enfermagem (Cravo).

[...] esclarece pelo menos as enfermeiras que nós tivemos contato esclareceram, teve uma em especial, não sei o nome agora mas, ela foi muito atenciosa, inclusive explicou muita coisa prá gente, sabe que às vezes a gente até depende do médico, mas a enfermeira, dependendo, ela explica mais ou menos quase que nem o médico, e essa enfermeira explicou prá gente e passou até uma tranquilidade prá gente, então acho que tá sendo ótimo (Lírio).

Depende, vai muito de cada um, com quem a gente vai falar da equipe, mas a maioria tão sempre dispostos, às vezes a gente pede algumas coisas, demoram um pouco prá atender, prá ir lá vê, mas no geral dão sempre as informações que eu quero ou indicam alguém que possa dá as informações. Ele tá três meses internado e tá tendo um tratamento muito bom, a gente tá até surpreendido (Orquídea).

Acho a equipe de enfermagem muito boa, toda vez que eu venho, tem alguém que fala: seu irmão tá assim, assim e assim. Então eu acho que ele tá em boas mãos, se depender da equipe de enfermagem ele não vai pro céu nunca! (Hortênsia).

Portanto, o contato da equipe de enfermagem 
com a família é fundamental para o estabelecimento de um vínculo de confiança, o que atenua o enfrentamento da internação de um membro da família. Posteriormente, essa confiança é transmitida ao paciente pelo familiar que se sente tranquilo e seguro.

Neste sentido,

se a família se sentir segura com o nosso cuidado, isto será fundamental para que o paciente também sinta-se seguro. Se a família valorizar os profissionais e sentirse bem atendida, os seus comentários junto ao paciente, o tranquilizarão e o farão suportar as dores, procedimentos ou o isolamento que porventura tenha que vir a passar ${ }^{(13: 78)}$.

O relacionamento da equipe com a família pode se tornar mais próximo quando uma necessidade é atendida, mesmo que não prevista da rotina do serviço. É o que se vê neste discurso:

Sim foi como eu esperava, porque quando não era horário de visita, como eu vim de longe, eu pedi, e acho que consegui expressar que eu queria ver ele um pouquinho. Eles deixaram eu dá uma olhadinha nele, fiquei super feliz! (Margarida).

Se a equipe de enfermagem tem um contato estreito e contínuo com a família e os pacientes, ela é capaz de perceber o que importa naquele momento para ambos. Para esse entrevistado, o fato de ver o paciente o tranquilizou, uma vez que veio de outra cidade para a visita. Por outro lado, o contato da equipe de enfermagem não é satisfatório para todos:

Prá falar bem a verdade prá você, eu com a equipe de enfermagem não tive contato nenhum, é muito difícil eu conversar com a parte da enfermagem. Eu sinceramente, eu falei, nesses dias, bem pouco com as enfermeiras, bem pouco (Violeta).

Neste caso, não ocorreu um contato efetivo entre o cuidador de enfermagem e o familiar. Conforme o discurso do sujeito, a equipe não esteve presente para cuidar dessa família e não houve uma relação interpessoal, abrangente, afetiva e próxima.

Em relação ao cuidado em UTI foi observado que

[...] o relacionamento da equipe de enfermagem com os familiares foi formal, burocrático e, sobretudo, despersonalizado; observou que o diálogo com a família foi superficial, que o enfermeiro estava ausente a maior parte do tempo e que os outros funcionários da unidade evitavam o contato com os familiares ${ }^{(3: 38)}$.

Desde o surgimento da doença, a família passa por crises e desajustes em que precisa sentir-se apoiada e segura, ter suas dúvidas esclarecidas e ter a certeza de que o paciente está sendo bem cuidado.

\section{CONSIDERAÇÕES FINAIS}

Considerando que a família do paciente é fundamental no seu processo de recuperação e resgatando o significado que ela atribui ao cuidado que deve atender às necessidades físicas e emocionais do paciente crítico e fortalecer o vínculo com o familiar. Neste estudo foram encontradas três categorias: o cuidado de enfermagem no entender do familiar, o qual revelou que o cuidado é composto de ações técnicas e dedicação; ações de enfermagem que contribuem para a recuperação do paciente, o que evidenciou a importância do carinho para a melhora do paciente; 0 contato da equipe de enfermagem com a família: um momento importante. Identificou-se que uma parcela significante dos familiares considerou o contato satisfatório e outra não teve suas expectativas atendidas.

Aponta-se que o familiar deseja dedicação da equipe e proximidade ao paciente, manifestadas por meio de atitudes e palavras de carinho, afetividade e solidariedade.

$\mathrm{O}$ contato da equipe de enfermagem com a família deve ir além de dar informações sobre o estado do paciente, ou possibilitar uma visita em horário alternativo. Esse contato pode ser simples, composto de pequenos detalhes, como um sorriso, um meneio positivo da cabeça, o contato dos olhos, um toque no braço, no ombro, um aperto de mão, o tom suave da voz. São atitudes que aproximam e fortalecem a relação equipe-paciente-família.

Finalizando, a enfermagem, em especial a enfermeira, precisa refletir sobre a importância da percepção da família sobre o cuidado e estabelecer contato de maior interação com as famílias, direcionando a sua equipe para essa conscientização.

\section{REFERÊNCIAS}

1. Ceccato SR Van der Sand ICP. O cuidado humano como princípio da assistência de enfermagem à parturiente e seus familiares [periódico na Internet]. Rev Eletron Enferm. 2001 [acesso em 2007 Out 06] 3(1). Disponível: http://www.fen.ufg.br/revista/index.htm. 
2. Waldow VR. O cuidado na saúde: as relações entre o eu, o outro e o cosmos. Rio de Janeiro: Vozes; 2004.

3. Maruiti MR, Galdeano LE. Necessidades de familiares de pacientes internados em unidade de cuidados intensivos [periódico na Internet]. Acta Paul Enferm. 2007 [acesso em 2007 Out 06] 20(1). Disponível: http:// www.scielo.br/scielo.php?script=sci_arttext\&pid= S0103-21002007000100007\&lng= en\&nrm=iso.

4. Freitas KS, Kimura M, Ferreira KASL. Necessidades de familiares de pacientes em Unidade de Terapia Intensiva: análise comparativa entre hospital público e privado [periódico na Internet]. Rev Latino-Am Enferm. 2007 [acesso em 2007 Out 17] 15(1). Disponível: http:// www.scielo.br/scielo.php?script=sci_abstract\&pid=S0 104-11692007000100013\&lng=pt\&nrm=iso\&tlng=pt.

5. Ratti A, Pereira MTF, Centa ML. A relevância da cultura no cuidado às famílias. Fam Saúde Desenv. 2005;7(1):608.

6. Santos CR, Toledo NN, Silva SC. Humanização em unidade de terapia intensiva: paciente-equipe de enfermagem-família. Nursing - Rev Téc Enferm. 1999;7:26-9.

7. Salicio DMBS, Gaiva MAM. O significado de humanização da assistência para enfermeiros que atuam em UTI [periódico na Internet]. Rev Eletron Enferm. 2006 [acesso em 2007 Out 17] (3):370-6. Disponível: http:// www.fen.ufg.br/revista/revista8_3/v8n3a08.htm.

8. Flick U. Uma introdução à pesquisa qualitativa. $2^{\mathrm{a}}$ ed. Porto Alegre: Bookman; 2004.

9. Minayo MCS. Pesquisa social: teoria, método e criatividade, organizadora. 9ªed. Petrópolis: Vozes; 2002.

10. Inaba LC, Silva MJP, Telles SCR. Paciente crítico e comunicação: visão de familiares sobre sua adequação pela equipe de enfermagem [periódico na Internet]. Rev Esc Enferm. USP. 2005 [acesso em 2007 Out 06] 39(4):423-9. Disponível: http://www.scielo.br/scielo.php ?pid=S0080-62342005000400008\&script=sci_abstract\& tlng $=p t$.

11. Souza SROS, Chaves SRF, Silva CA. Visita na UTI: um encontro entre desconhecidos. Rev Bras Enferm. 2006;59(5):609-13.

12. Nascimento ERP, Trentini M. O cuidado de enfermagem na Unidade de Terapia Intensiva (UTI): teoria humanística de Paterson e Zderad [periódico na Internet]. Rev Latino-Am Enferm. 2004 [acesso em 2008 Abr 14] 12(2): 250-7. Disponível: http://www.scielo.br/ pdf/rlae/v12n2/v12n2a15.pdf.
13. Silva MJP. O papel da comunicação na humanização da atenção à saúde. Bioética. 2002;10(2):73-88. 